\title{
Discussion on the training mode of engineering masters of school-enterprise associate laboratory
}

\author{
XIANG Jian-hua \\ School of Mechanical and Electric Engineering \\ Guangzhou University \\ Guangzhou, China \\ E-mail: xiangjh@gzhu.edu.cn
}

GAN Zhi-jian

School of Mechanical and Electric Engineering

Guangzhou University

Guangzhou, China

E-mail: 379191321@qq.com

\author{
ZHOU Chao \\ School of Mechanical and Electric Engineering \\ Guangzhou University \\ Guangzhou, China \\ E-mail: superzc@tom.com
}

\author{
ZHANG Chun-liang \\ School of Mechanical and Electric Engineering \\ Guangzhou University \\ Guangzhou, China \\ E-mail: nhzcl@163.com \\ LIU Gui-yun \\ School of Mechanical and Electric Engineering \\ Guangzhou University \\ Guangzhou, China \\ E-mail: liugy@gzhu.edu.cn \\ CHEN Cong-gui \\ School of Mechanical and Electric Engineering \\ Guangzhou University \\ Guangzhou, China \\ E-mail: cg6568@126.com
}

\begin{abstract}
In consideration of talent shortage of engineering masters and low quality of engineering education, and in order to effectively strengthen the engineering practice training, this paper elaborates on the significance of creating school-enterprise associate laboratory to train engineering master talents on the base of CDIO engineering education principle. This paper orients towards tutors' research projects and targets at the training of engineering comprehensive abilities, therefore the practice education of engineering masters and actual demand of enterprises can be closely integrated and students' comprehensive qualities can be improved in practice. Meanwhile, this paper discusses the concrete implementation methods and suggestions of creating school-enterprise associate laboratory. The main purpose is to explore the development practice of CDIO engineering education in colleges and universities by virtue of school-enterprise associate laboratory.
\end{abstract}

Keywords-CDIO engineering education principle; schoolenterprise associate laboratory; engineering master training

\section{INTRODUCTION}

The innovative and practical abilities of engineering masters reflect in the settlement of actual problems in engineering area on the basis of professional knowledge and skills. With the acceleration of China's modernization process, the training orientation of engineering masters and qualities of engineering education shall be closely integrated with enterprises' demands. The European and American exploration experience indicates that the reform orientation of engineering master education shall focus on engineering practice training and the training of various abilities, and emphasizes synthesis and integration in content, including individual knowledge of engineering science and technology, abilities of scientific research and technology development, abilities of lifelong learning, abilities of knowledge integration and information processing, abilities of communication and teamwork cooperation, abilities of engineering leadership, organization and management and etc ${ }^{[1,2]}$.

At present, engineering master occupies $50 \%$ of the total number of masters in school in China, while only a small number of them can satisfy the engineering demands of domestic and foreign enterprises. In order to solve the existing problems of engineering education, domestic experts, scholars and education administrators try to explore theoretical methods of engineering master education reform and make some attempts in some aspects. This paper, on the basis of CDIO engineering education principle, discusses the significance and suggestions of creating school-enterprise associate laboratory to train engineering masters ${ }^{[3,4]}$.

\section{CDIO ENGINEERING EDUCATION}

In the late 1990s, the International Research Organization, constituted by a team headed by Professor Ed. Crawley, academician of Faculty of Engineering at MIT as well as four 
universities including Royal Institute of Technology, was funded by Knut and Alice Wallenberg Foundation and created CDIO Engineering Education Principle and set up CDIO International Cooperative Organization after four years' exploration and research, and hereby established the modern engineering education mode. CDIO, representing conceive, design, implement and operate, is the whole life process of modern industrial products from design research to operation and finally to retirement.

CDIO mode, in order to cultivate engineering students' knowledge, abilities and qualities to survive and grow in the modern engineering surroundings, tries to regard Project Implementation and Productization of Engineering Practice Outcome as the organization principles of engineering practice education, and cultivates students' communication skills and abilities or consciousness of controlling large scale system. Conceive, the first part of CDIO teaching principle, includes comprehensive consideration of technology and enterprise strategy, formulation of outline plans, discussion on the project's technical feasibility and formulation of technical programs. Design, the second part of CDIO, includes the necessary designs for the project implement like design calculation, draft plan and layout design. Implement, the third part of CDIO, converts design scheme into actual products, including design and manufacture of hardware, and programming and debugging of software. Operate, the fourth part of CDIO, is the process of assessing products in implementation, including revise, improvement or elimination of designs. In this context, CDIO teaching principle organizes teaching by the life cycle of engineering project, and the teaching method emphasizes integral consciousness and system concept and can cultivate students' comprehensive abilities of settling problems.

\section{SIGNIFICANCE OF ESTABLISHING SCHOOL-ENTERPRISE ASSOCIATE LABORATORY}

\section{A. Establishing school-enterprise associate laboratory is the best way to apply CDIO Engineering Education Principle to train engineering masters}

School-enterprise associate laboratory provides work platform and practice base for engineering masters, meanwhile supports and encourages engineering masters to experientially learn products, work flow, system construction, teamwork knowledge and socialization. School-enterprise associate laboratory, orienting towards tutors' research projects and targeting at the training of engineering comprehensive abilities, enables engineering students to organically integrate the CDIO principle into the master of engineering research by the overall operating process from the conception and selection of research subject to the design and realization of solution and finally to the implementation of whole project.

The core of CDIO Engineering Education Principle is to apply what has been learnt and to use the knowledge flexibly. Considering that enterprise is the practical subject of engineering knowledge, the degree of correlation between the professional knowledge education of colleges and engineering demands of enterprises shall be improved, and the pertinence and applicability shall also be improved. For colleges, the establishment of school-enterprise associate laboratory to train engineering masters is just the actual application of CDIO engineering education ${ }^{[1]}$.

\section{B. Establishing school-enterprise associate laboratory to train engineering masters is an important way to test high caliber talent group}

The establishment of school-enterprise associate laboratory can play an important role in testing learning outcome of engineering masters, and also can test the postgraduate's abilities of discovering knowledge, acquiring knowledge, applying knowledge, sharing knowledge and spreading knowledge. For example, the establishment of the quality evaluation committee, whose members includes teachers, students and judges from enterprises. More importantly, the judgment on the CDIO abilities of engineering masters by the judges from enterprises is relatively more objective and accurate, thus making up for the deficiency of other judges. The objective and overall judgment on the master students upon graduation, and specific practice and training in deficient aspects can provide guarantee for the improvement of comprehensive qualities of engineering masters ${ }^{5]}$.

Engineering talent is the important pillar of promoting enterprise development and ensuring product quality. The acceleration of training engineering talents is an urgent task for our country's education, but also a long-term strategy for enterprises to maintain sustainable development. For enterprises, the establishment of school-enterprise associate laboratory is beneficial to the improvement of enterprise connotation, and engineering masters can directly work independently in the enterprise upon graduation ${ }^{[6]}$.

\section{Establishing school-enterprise associate laboratory to train engineering masters is an important way to improve teacher group}

The establishment of school-enterprise associate laboratory can change the mind of paying little attention to the teachers' engineering practice abilities and merely emphasizing the linkage to research products. Meanwhile, it can solve the present difficulties like insufficient experience of young tutors and non-close relationship between enterprise tutors and college tutors. For example, the resident system of tutor representatives can be established, and some young tutors are selected from the tutor group to reside in school-enterprise associate laboratory. On the one hand, young tutors can comprehend engineering practice, solve engineering problems and understand enterprise demands. On the other hand, young tutors can improve their own engineering comprehensive abilities in concrete work. By such virtue, tutors can not only improve professional skills, but be acquainted with enterprise production and management as well as job requirements, which are more beneficial for tutors to carry out teaching work.

\section{THE CONCRETE IMPLEMENTATION METHODS AND SUGGESTIONS}

CDIO engineering education principle emphasizes the training of engineering practice, and the main carrier of 
engineering practice shall be the enterprise. In the course of talent training, the principal line shall be the cultivation of students' overall professional quality, ability of technology application and employment competitiveness ${ }^{[7]}$. Meanwhile, the two different educational surroundings and educational resources of colleges and enterprises shall be made full use of. By virtue of bilateral interaction and long-term cooperation between colleges and enterprises, high-quality skilled personnel is trained at the combination of theoretical study and fundamental training in college with actual work experiences, thus integrating theoretical study and practice training of engineering masters with innovative design and market promotion of products. However, several problems below shall be seriously researched and solved in the course of training.

\section{A. The determination of the number of engineering masters}

How does enterprise select engineering postgraduates to participate in the training, and what is the suitable quantity of students? It may fail to achieve the proper effect once the enterprise selects too many students because of limited resource. On the other hand, it may lose the value of engineering education once too few students are selected. Therefore, the optimal student number shall be explored, and the necessary theoretical knowledge and computer application abilities in participation of training shall also be explored. Sequentially, the explored results shall be fed back to theory teaching to improve the study and teaching of theoretical knowledge, thus achieving the virtuous circle goal of promoting theoretical teaching and studying by virtue of actual production, and improving practice abilities and innovation abilities by virtue of theoretical teaching and study.

\section{B. The individual cooperation in the project team}

What kinds of students shall be selected to participate in enterprise training, and how every participating student shall be taught in accordance with their individual professional background, interest and specialty? Every student may vary in interest and specialty, therefore the project-oriented schoolenterprise associate laboratory enables postgraduates from different subjects and majors to participate in, and allocates concrete tasks in accordance with individual interest and specialty, as well as enables the students to learn from others' strong points to offset their own weaknesses, thus achieving the purpose of completing every task by virtue of teamwork. Therefore, it is of vital importance to conduct individualized education in accordance with the students' individual professional background, interest and specialty.

\section{Subject selection}

What kind of concrete practice subject shall be determined so that the practice activities and theoretical study of participating students can complement with each other, and innovation ability and manipulative ability of participating students can be improved. The present mode of postgraduate theoretical study mainly presents as classroom teaching in accordance with textbooks. Generally speaking, the textbook content is mostly the summary of predecessors' viewpoints, theories and knowledge, and the study of theoretical courses in class is mostly the comprehension and acceptance of existing viewpoints, theories and knowledge. Therefore, students lack independent thinking, innovation and experience of actual problems. While science and technology calls for an expanding mind and constant challenge against the existing concepts and knowledge, which is likely to give birth to a first-class scientist and engineer. Therefore, it is of vital importance to integrate theoretical study with practical study, and inspire the study passion from the students' inside by virtue of subject selection.

\section{CONCLUSIONS}

In order to cope with the fierce competition in international society and get accustomed to new demands of economic and social development in China, the comprehensive abilities of engineering masters shall be improved and be combined with the enterprise's demand in the training course to improve the quality of talent training. This paper, combined with CDIO Engineering Education Principle, proceeding from the demands of engineering innovation ability training, explores the training mode of engineering innovative talents to overall improve the quality of engineering masters, and focuses on training innovative and engineering talents appropriate to meet the demands of economic and social development.

\section{ACKNOWLEDGMENTS}

This research were supported by the Natural Science Foundation of Guangdong Province (S2013010013469), the project of DEGP (Yq2013127, 2013KJCX0143, 2014A010105053), Guangzhou research program (201510010069), and Guangzhou Key Laboratory for Monitoring and Control of Electromechanical Equipment (2060402)

\section{REFERENCES}

[1] WANG Rui-hu. The construction of training architecture for application-oriented graduates based on CDIO-excellent engineer project[J]. Journal of Chongqing University of Arts and Sciences (Natural Science Edition), 2012, 31(2): 97-101.

[2] YUAN Jian, GE You-hua, NI Xiao-hua.Reform on Talents Training in Excellent Program[J]. CHINESE GEOLOGICAL EDUCATION, 2013, 1: $8-10$

[3] Gu Peihua, Bao Nengsheng, Kang Quanli, Lu Xiaohua, Xiong Guangjing, Lin Peng, Chen Yan. CDIO in China (Part I)[J]. Research in Higher Education of Engineering, 2012, 3: 24-40.

[4] Gu Peihua,Bao Nengsheng,Kang Quanli,Lu Xiaohua,Xiong Guangjing,Lin Peng,chen Yan. CDIO in China (Part II) [J]. 2013, 5:3445 .

[5] Yanbin Shi, Chonghai Xu,Guangchun Xiao. Exploration on the Cultivation for Professional Degree Postgraduate Majoring in Mechanical Engineering Based on CDIO [C]. 2013 3rd International Conference on Social Sciences and Society.135-139.

[6] YU Bao-hua. Exploration of the model for master of education programs based on the concept of CDIO[J]. Journal of Graduate Education, 2012, 5: 60-65.

[7] ZHANG Guo-bin,ZHANG Shu-jun,LIU Chun-cheng,LIU Yue,XU Zeng-mei.Cultivation of students' practice ability based on CDIO model[J].LABORATORY SCIENCE， 2014， 17(1): 126-131. 